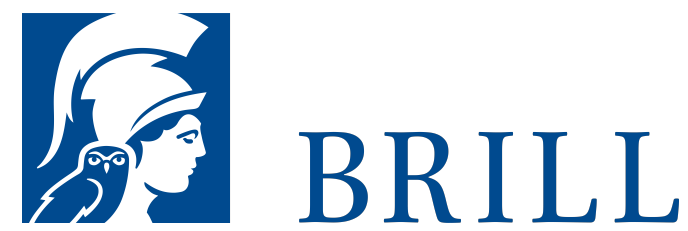

\title{
Bulimie und Magersucht
}

\section{Ratgeber für Eltern}

Author: Kirsten Borgstedt

Leidet Ihr Kind an Essstörungen? Jagt es einem Schönheitsideal nach, das es gefährdet? Fürchten Sie, dass sich diese Störungen zu einer Sucht entwickeln könnten oder es schon getan haben? Woran kann man erkennen, dass ein Kind tatsächlich von Magersucht oder Bulimie betroffen ist?

Viele Jugendliche, vor allem pubertierende Mädchen, zunehmend aber auch Jungen, finden sich zu dick - oft der Beginn einer langjährigen Leidensphase. Zwanghaft wird der eigene Körper zum einzigen Lebensinhalt. Aus diesem Teufelskreis von falscher Selbstwahrnehmung und Abnehmenwollen will Ihnen dieser HELP-Band Wege zeigen zurück ins Leben!

Mit ihrer intensiven Erfahrung aus dem Therapiealltag einer Fachklinik erklärt die Autorin psychische Ursachen von Essstörungen, zeigt grundlegende Symptome und hilft Eltern durch wertvolle Tipps, ihren Kindern effizient beizustehen, um diese lebensbedrohliche Erkrankung zu überwinden.

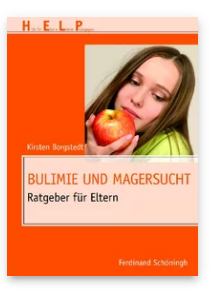

Pages: 112 Seiten

Language:

German

Subjects:

General,

Education

Publisher: Brill |

Schöningh

Series:

HELP - Hilfe für

Eltern, Lehrer,

Pädagogen

E-Book (PDF)

Released online:

$10 \mathrm{Feb} 2 \mathrm{O} 2 \mathrm{O}$

ISBN: 978-3-

657-77351-0

List price

Paperback

Publication date:

11 Mar 2013

ISBN: 978-3-

506-77351-7

List price 
Kirsten Borgstedt, Dipl.-Psych., Dr. phil., ist Gestalttherapeutin und Gesundheitspsychologin. Nach dem Studium war sie wissenschaftliche Angestellte und Lehrbeauftragte an der Universität Bielefeld und ist zudem freie Trainerin im Bereich der psychologischen Gesundheitsförderung; seit 2008 ist sie Psychotherapeutin in einer Fachklinik für Essstörungen.

For more information see brill.com

Order information: Order online at brill.com +44330 3330049 | customerservices@brill.com Submission information: brill.com/authors

Titles published by Brill | Fink, Brill | mentis or Brill | Schöningh: +49(o)71 5413279216 | brill@brocom.de 